\title{
Finite elements modelling of a large water table aquifer in transient conditions
}

\author{
A. Dassargues \\ L.G.I.H., Laboratoires de Géologie de l'Ingénieur, d'Hydrogéologie et de Prospection \\ géophysique, Bâtiment 19 - Sart Tilman, Université de Liège, 4000 - Liege, Belgium
}

\section{J.-P. Radu and R. Charlier}

M.S.M., Mécanique des Solides et des Matériaux, Bâtiment du Génie Civil - Val Benoît, Université de Liège, 4000 - Liege, Belgium

\begin{abstract}
A chalky aquifer located near Liege (Belgium), is recharged by infiltration through the overlying loess. Wells and collecting tunnels produce a daily flow of $60000 \mathrm{~m}^{3}$ out of this aquifer when hydrogeological balances have shown that an average yield of $100000 \mathrm{~m}^{3} /$ day should be possible.

Finite element modelling has been developed to foresee the evolution of the water table to get some additional information especially about the main drainage axis.

The transient flow constitutive laws are recalled in confined and unconfined aquifers. A new law is proposed to model the water table surface in transient conditions and with a fixed meshing network. Using the local flow equilibrium and the virtual power principle, the FEM formulation is set up. The time integration and the iteration technique are shortly discussed.

The 3D discretization and the modelling of the entire aquifer has been realized. The problem requires about 3600 DOF and 2670 8-nodes isoparametric brick finite elements. The modelling has been quite delicate because of the geometric complexity of the different geological layers. This complexity justifies fully the use of the finite element method; there is indeed a great diversity of geological characteristics and the range of the different permeabilities is very wide. Sensitivity of the model to permeabilities and storage coefficient variations has been studied and various numerical problems have been notified.

The calibration procedure is described in its main steps, and the most significant results are presented.
\end{abstract}

Key Words: groundwater, modelling, finite element, transient state, unsteady conditions, water table aquifer, water table modelling, 3D modelling, regional aquifer modelling, unconfined aquifer modelling.

\section{INTRODUCTION}

The modelled aquifer is located near Liège in Belgium (Fig. 1). Nowadays, it provides the water supply (more or less $60000 \mathrm{~m}^{3} /$ day) for the city of Liège and its suburbs. The studied zone corresponds to an area of $350 \mathrm{~km}^{2}$ called 'Hesbaye' and the geological nature of the reservoir is mainly chalk. A new numerical code has been developed to allow the Water Office to get an integrated analysis of such an aquifer. This analysis becomes more and more essential to get the best development possible avoiding total or partial depletion of the aquifer ${ }^{1}$.

The method presented hereafter is based on a heat conduction analogy. It makes possible the simulation in transient conditions of a water table surface, in a regional model with fixed finite element meshing network.

\section{DATA}

The complete collection of data includes information concerning geology, hydrology, geomorphology and geophysics.
The geological conditions (Fig. 2) can be summed up by this series (from the bottom to the top):

a. Primary rocks with limestones in the SE part, in contact by a fault shift with siltstones, sandstones and shales.

b. Secondary formations essentially composed by Cretaceous layers ${ }^{2}$ on 20 to $100 \mathrm{~m}$ of thickness:

- a layer of hardened calcareous clay (called 'smectite') considered as the bottom of the aquifer (thickness: $+/-10 \mathrm{~m}$ )

- the compact solid white chalk (called lower chalk) with main water circulations in the fractured zones (thickness: $20 \mathrm{~m}-40 \mathrm{~m}$ )

- a thin $(<1 \mathrm{~m})$ layer of hardened chalk (called 'hardground')

- the grey chalk (called upper chalk) more exposed to alteration phenomena (thickness: $10-15 \mathrm{~m}$ )

- a residual conglomerate.

c. Tertiary and Quaternary formations:

- sand in some places

-2 to $20 \mathrm{~m}$ of loess 
- recent alluvial colluvial deposits.

Cross-sections and maps have been drawn using all the geological and piezometric data collected from more than 500 holes $^{3}$.

Hydrodynamic parameters have been provided by 150 pumping tests in the different lithological units. The following ranges of values are found:

$$
\begin{array}{ll}
\text { - loess } & : 1.10^{-9} \leqslant K \leqslant 2.10^{-7} \mathrm{~m} / \mathrm{s} \\
& ? \leqslant S \leqslant ? \\
\text { - residual conglomerate } & : 1.10^{-5} \leqslant K \leqslant 8.10^{-3} \mathrm{~m} / \mathrm{s} \\
& 0.05 \leqslant S \leqslant 0.10 \\
\text { - upper chalk } & : 2.10^{-4} \leqslant K \leqslant 5.10^{-3} \mathrm{~m} / \mathrm{s} \\
& 0.07 \leqslant S \leqslant 0.15 \\
\text { - lower chalk } & : 1.10^{-5} \leqslant K \leqslant 5.10^{-4} \mathrm{~m} / \mathrm{s} \\
& 0.05 \leqslant S \leqslant 0.15
\end{array}
$$

In water table conditions, the unconfined storage coefficients $(S)$ are approximated by effective porosity $(n)$ of each lithological unit. For this aquifer the measured

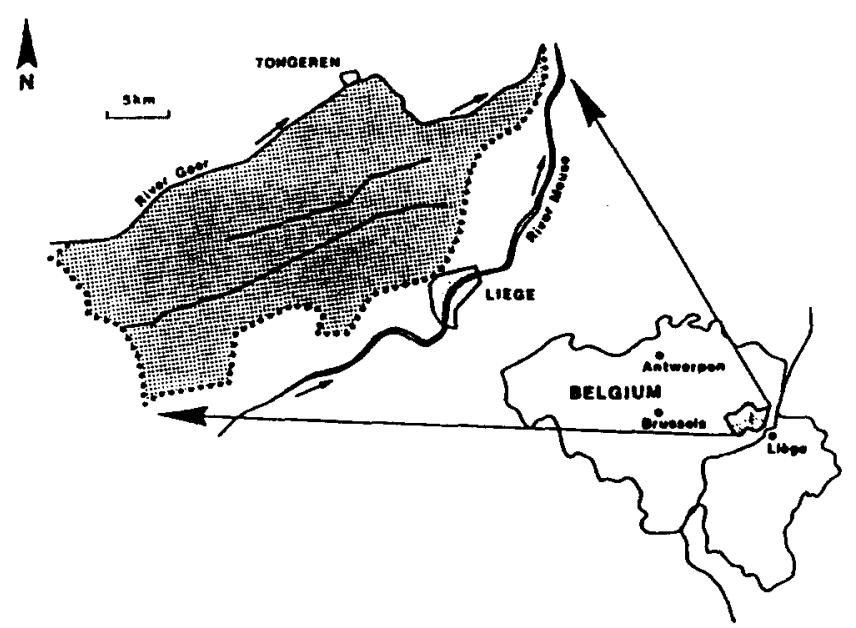

Fig. 1. Location map of 'Hesbaye' aquifer values of $S$ are very high because the two porosities of the chalk are taken into account (fracture and pore porosities ${ }^{4}$ ).

Since 1951, piezometric levels have been measured with great care. Evolution of the piezometric level in function of the time has been recorded at different 'check points' of the aquifer. Piezometric maps and sections relative to each year have been drawn ${ }^{3}$.

The active hydrographic network is directed to the N.NW as the topographic levels presents a slow decrease to this direction. This network is sparse because many 'dry valleys' (mainly due to chalk fracturation and karstification) are working as main drainage axis in the subsoil.

The river flow, the pumping adits discharge and the rainfall recharge by infiltration are well known time depending data.

The finite element method seems very well adapted to model such a geometrically complex and heterogeneous problem.

Isoparametric finite elements can easily follow the limits of the layers or boundaries. Porous medium elements, gallery elements and infiltration elements can be combined.

The developments presented hereafter have been implemented in the finite element code LAGAMINE which has been developed during the past six years in the M.S.M. department, University of Liège ${ }^{5}$.

\section{MODELLING THE WATER TABLE AQUIFER IN TRANSIENT CONDITIONS}

The computation of the water table position is the most difficult problem to solve. A number of authors have developed finite element codes for searching the free surface and adapting the mesh by geometrical analysis. See for example Taylor and Brown ${ }^{6}$, Desai ${ }^{7}$, Desai and $\mathrm{Li}^{8}$, Gioda and Cividini ${ }^{9}$, Bruch ${ }^{10}$, Bruch and Grilli ${ }^{11}$ uses the boundary elements method and a variable mesh.

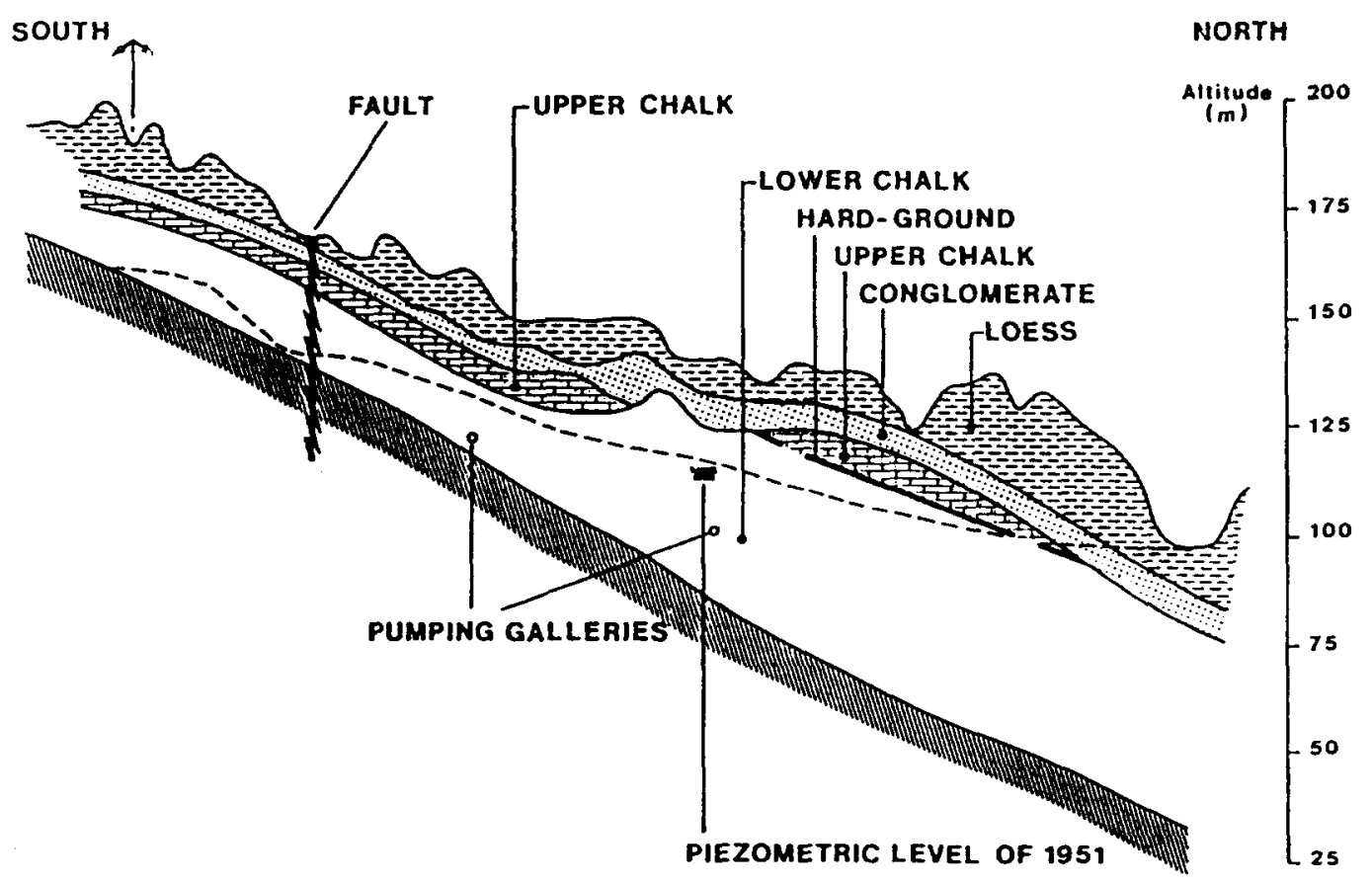

Fig. 2. Vertical cross-section 


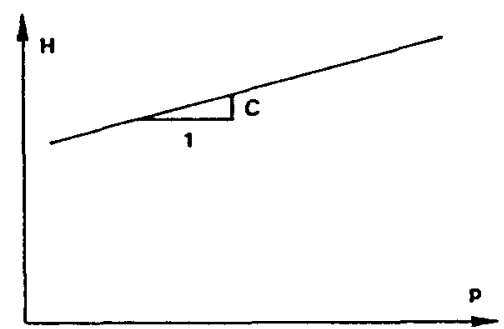

Fig. 3. Storage law for a confined aquifer

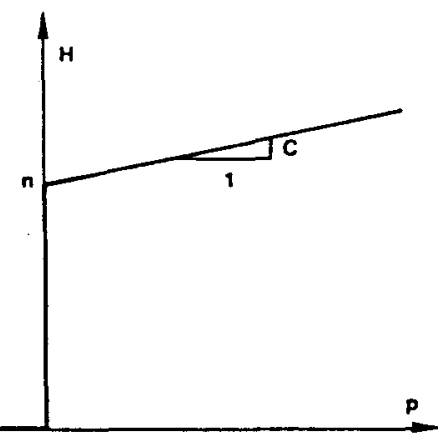

Fig. 4. Storage law for an unconfined aquifer

Piette $^{12}$ and Piette and Cescotto ${ }^{13}$ use a fixed mesh, but eliminate the integration points lying above the water table. All these analyses are based on a particular free surface shape. The free surface motion is simple and generally vertical, so that an important part of the finite element code is dedicated to geometrical computations.

The method presented here is drawn from the modelling by 'enthalpic technique' of the phase changes in heat conduction problems. Phase changes occur at constant temperature, with storage of heat. In our case, the geological porous medium passes from unsaturated to saturated state at a constant zero pressure with storage of water.

The constitutive relation of the fluid flow in porous media is Darcy's law. It links the fluid velocity $f$ to the pore pressure gradient. We note here:

$p$ the pressure

k the permeability tensor (anisotropic media)

$\gamma$ the fluid specific weight

$\mathbf{e}_{z}$ the gravity direction vector (normed).

In transient state, the storage of fluid $H$ in the soil pores varies with respect to the pore pressure and to the saturation degree. Therefore, a second constitutive relation, named here the storage law, must be used.

In a confined aquifer, Darcy's law has the following form:

$$
\mathbf{f}=\frac{\mathbf{k}}{\gamma} \operatorname{grad} p-\mathbf{k e}_{z}
$$

The storage law will express the modification of the pore volume when the pore pressure varies. It is linked to the elastic or elasticplastic soil skeleton strains.

The fluid volume variation is $\dot{H}$ :

$$
\dot{H}=C \dot{p}
$$

$C$ is the confined storage coefficient, function of the porosity and the skeleton mechanical characteristics.

$k$ and $C$ are generally supposed to be constant. Then the problem is linear and computations not too expensive.

For an unconfined aquifer, the motion of the water table is governed by a special storage law. Most authors link this motion to the fluid velocity $f$ and the porosity $n$. If $\mathbf{v}$ is the normal to the table, the following surface equilibrium relation can be obtained:

$$
v^{T} \mathbf{v}=n \mathbf{f}^{T} \mathbf{v}
$$

This geometrical evolution law does not describe completely the table displacement vector, but only one of its components. The other components are generally determined assuming that only vertical table displacements occur. This last hypothesis is a main limitation of the technique.

The new method is not based on boundary geometrical considerations but on a volumic storage equation. When the soil is saturated, the pore pressure is positive (if the atmospheric pressure is taken as zero on the pressure scale), and the storage constitutive law is governed by equation (2) (Fig. 3). When the soil is unsaturated, the pore pressure is null, and the fluid content $H$ is comprised between zero and the unconfined storage coefficient $S$. Negative pore pressures are meaningless (Fig. 4).

$$
\begin{aligned}
& p>0 \rightarrow H=S+C p \\
& p=0 \rightarrow O \leqslant H \leqslant S \\
& p<0 \rightarrow H=O \text { (unphysical) }
\end{aligned}
$$

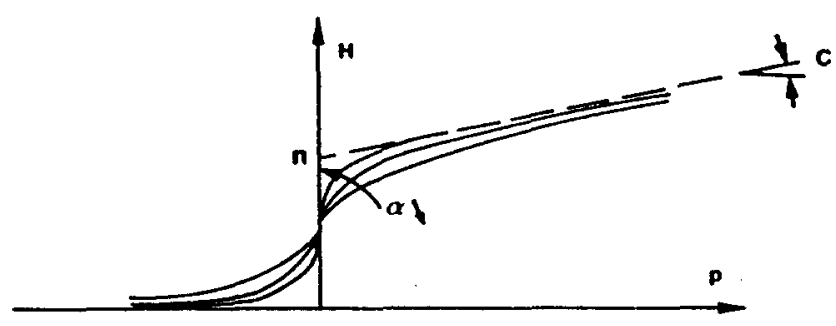

Fig. 5. Relaxed storage law for an unconfined aquifer
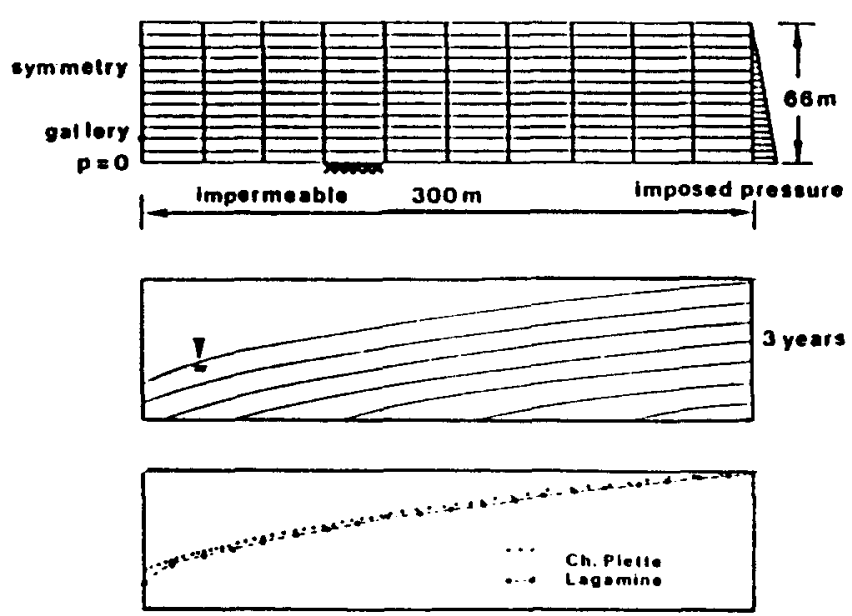

Fig. 6. Comparison of the results with Piette's problem 

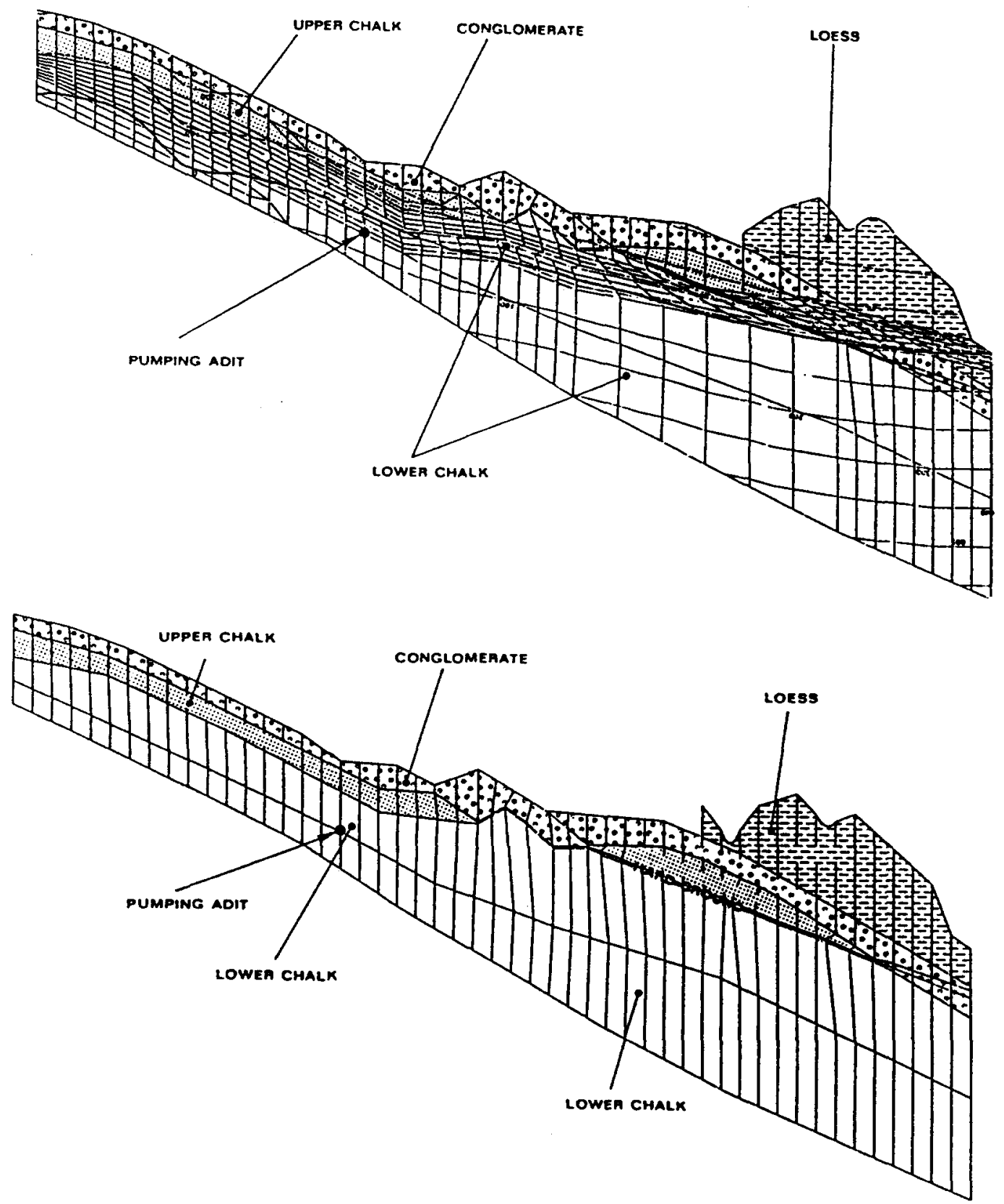

Fig. 7. Two discretizations of the same cross-section

The free surface motion is governed by the saturationunsaturation of the soil pores.

The transient seepage modelling is not based on the relation $H=f(p)$ but on the derivative of this relation:

$$
\dot{H}=f(\dot{p})
$$

As it appears on Fig. 4, there is a discontinuity of $H$ at $p=0$, difficult to implement in a finite element code. Therefore, equation (4) is approximated and smoothed by a polynomial function or an arc-tangent function. This second solution is adopted in the code LAGAMINE (Fig. 5):

$$
H=S\left(\frac{1}{\pi} \operatorname{arctg}\left(\frac{p}{\alpha}\right)+\frac{1}{2}\right)+C\langle p\rangle
$$

with

$$
\begin{array}{ll}
\langle p\rangle=p & \text { if } p>0 \\
\langle p\rangle=0 & \text { if } p \leqslant 0
\end{array}
$$

The approximation is better with a smaller coefficient $\alpha$ (Fig. 5). This method is therefore a kind of penalty method.

With this approximation, the negative pore pressure domain contains a small amount of water (as small as the penalty is good). As Darcy's law (equation (1)) is valid only for saturated media a slightly modified Darcy's law had to be used in this zone, taking into account the amount of saturation:

$$
\mathbf{f}=\frac{\mathbf{H}}{\mathbf{S}}\left(\frac{\mathbf{k}}{\gamma} \operatorname{grad} p-\mathbf{k e}_{\mathbf{z}}\right)
$$

\section{FORMULATION OF THE FEM}

The external and internal virtual powers are developed under a virtual allowable perturbation of the pressure $p$ (with respect to the imposed pore pressure).

The global equilibrium of the fluid flow in the entire 


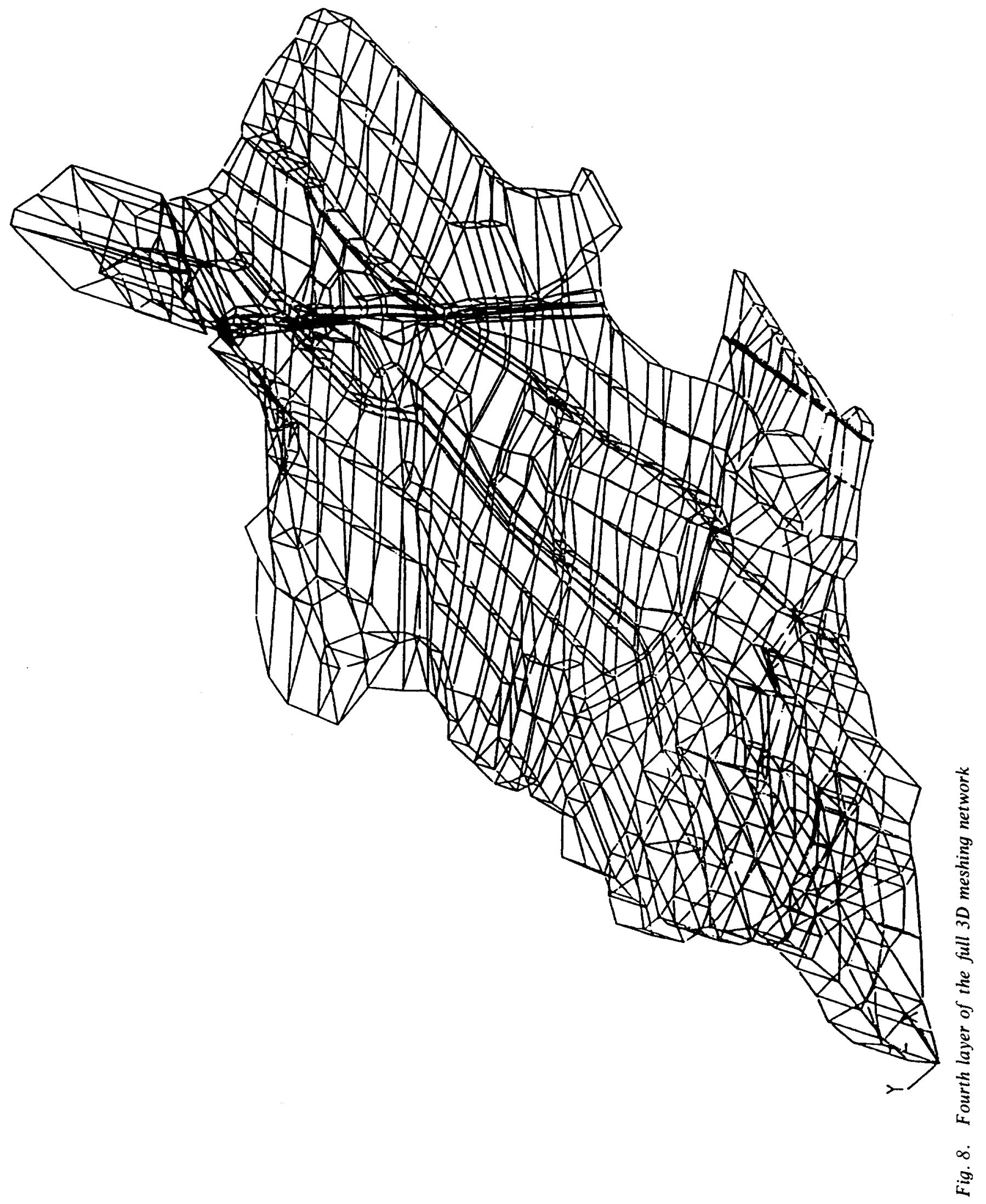


studied domain is obtained when the internal and external virtual powers are equal for any virtual pressure perturbation:

$$
\delta W_{E}=\delta W_{I}
$$

Using the virtual power equations, isoparametric finite elements are built and implemented in a classical finite element code:

- plane axisymmetric parabolic elements, 8-node squares and 6-node triangles;

$3 \mathrm{D}$ brick-elements with 1 to 3 nodes on each edge, parabolic and cubic polynomials can be used;

- 3D lines, for one-dimensional flow as in pumping adits;

3D thin elements (for faults).

In each element, the volumic integration is performed numerically using the Gaussian scheme.

The best iteration technique is the well-known Newton-Raphson technique, based on the tangent iteration matrix $\mathbf{K}$ (called stiffness matrix in structural mechanics). This matrix is obtained by derivation of the so-called nodal flows with respect to the nodal pore pressures. The dependence of the permeabilities upon the nodal pore pressures induces a nonsymmetrical matrix.

When the nonlinearities, i.e., the water table fluctuations, are small during the time steps, a new matrix is computed only after some iterations.

\section{TESTS}

One of the most important tests was realized on the problem of Piette ${ }^{12,13}$. She has computed the equilibrium (steady-state) position of a water table in a vertical plane state soil area. At the initial time, the soil is completely saturated. The isotropic permeability is $k=1.510^{-5} \mathrm{~m} / \mathrm{s}$ and the effective porosity is $S=30 \%$. A small collecting gallery is burrowed $55 \mathrm{~m}$ in depth. The gallery pressure (initially $550 \mathrm{KPa}$ ) is decreased very quickly to the atmospheric pressure. We have computed the evolution of the pore pressures in the domain and the evolution of the input and output flows. The mesh is composed of 120 elements and 405 nodes (Fig. 6).

The final position of the water table computed by the code is quite similar (Fig. 6) to the results of Piette. The quasi-steady state is obtained after about 3 years.

Then, the cross-section of the 'Hesbaye' aquifer presented on Fig. 2 has been discretized with two different meshing networks (Fig. 7). Generally, results have shown a too fast rise of the piezometric levels in spite of a choice $k_{\text {horizontal }}=10 . k_{\text {vertical }}$ in the chalk layers. These bad results are mainly due to the difficulty in calibrating the vertical cross-sections.

More important was the fact that the two discretizations have given very similar results. This verification was very important to pass on a $3 \mathrm{D}$ model avoiding too small elements.

\section{3D MODEL OF 'HESBAYE' AQUIFER}

The 3D network has to take into account much geometrical data: location of pumping wells and adits, main geological faults, limits of geological units or hydrogeological basin ${ }^{3}$.

The mesh is composed of 3300 8-node brick elements and 3600 nodes. As an example, Fig. 8 shows the complexity of the meshing network in the fourth layer.

Pumping adits are represented by '3D tube elements' with infinite permeability in regard to the neighbouring elements.

Initial conditions are the piezometric levels of 1951 , from which the mathematical simulation is started in transient conditions.

Prescribed potential (Dirichlet conditions) are imposed on the northern boundary at the River Geer. The other boundaries are assumed to be impervious (Neuman condition) as it seems that no flow is to be considered through these geological boundaries.

Hydrodynamic parameters affected in each element are permeability $K$ and storage coefficient $S$. Different kinds of materials have been defined corresponding, before calibration, essentially to the different geological units.

During the calibration procedure, the main difficulties encountered were the following:

- the introduction of infiltration recharge by a means numerically compatible with the modelling of the water-table (in fact by 'flow elements' with normal uniform flow),

the introduction of very high contrasts in the permeability values in the immediate neighbourhood of the pumping adits,

- the introduction of the prescribed concentrated pumping flows in these adits avoiding an important depression cone.

After this, the calibration procedure has consisted mainly of:

(a) the fitting of the different hydrodynamic parameters of each material,

(b) some little modifications in the repartition of these different materials. These adjustments are made on basis of comparisons between measured and computed values of piezometric levels on the maps and the sections and at some 'check points'.

At the end of the calibration procedure, the final values of the different parameters are:

Material 1: lower chalk:

$$
K=2.10^{-4} \mathrm{~m} / \mathrm{s} \text { and } S=0.10
$$

Material 2: 'dry valley':

$$
K=4.10^{-3} \mathrm{~m} / \mathrm{s} \text { and } S=0.12
$$

Material 3: 'hard ground':

$$
K=8.10^{-5} \mathrm{~m} / \mathrm{s} \text { and } S=0.08
$$

Material 4: upper chalk:

$$
K=5.10^{-4} \mathrm{~m} / \mathrm{s} \text { and } S=0.12
$$

Material 5: alluvial deposits and residual conglomerate:

$$
K=1.10^{-5} \mathrm{~m} / \mathrm{s} \text { and } S=0.15
$$

Material 6: conglomerate and loess:

$$
K=1.10^{-6} \mathrm{~m} / \mathrm{s} \text { and } S=0.15
$$

Material 7: 'fault material':

$$
K=2.10^{-3} \mathrm{~m} / \mathrm{s} \text { and } S=0.10
$$



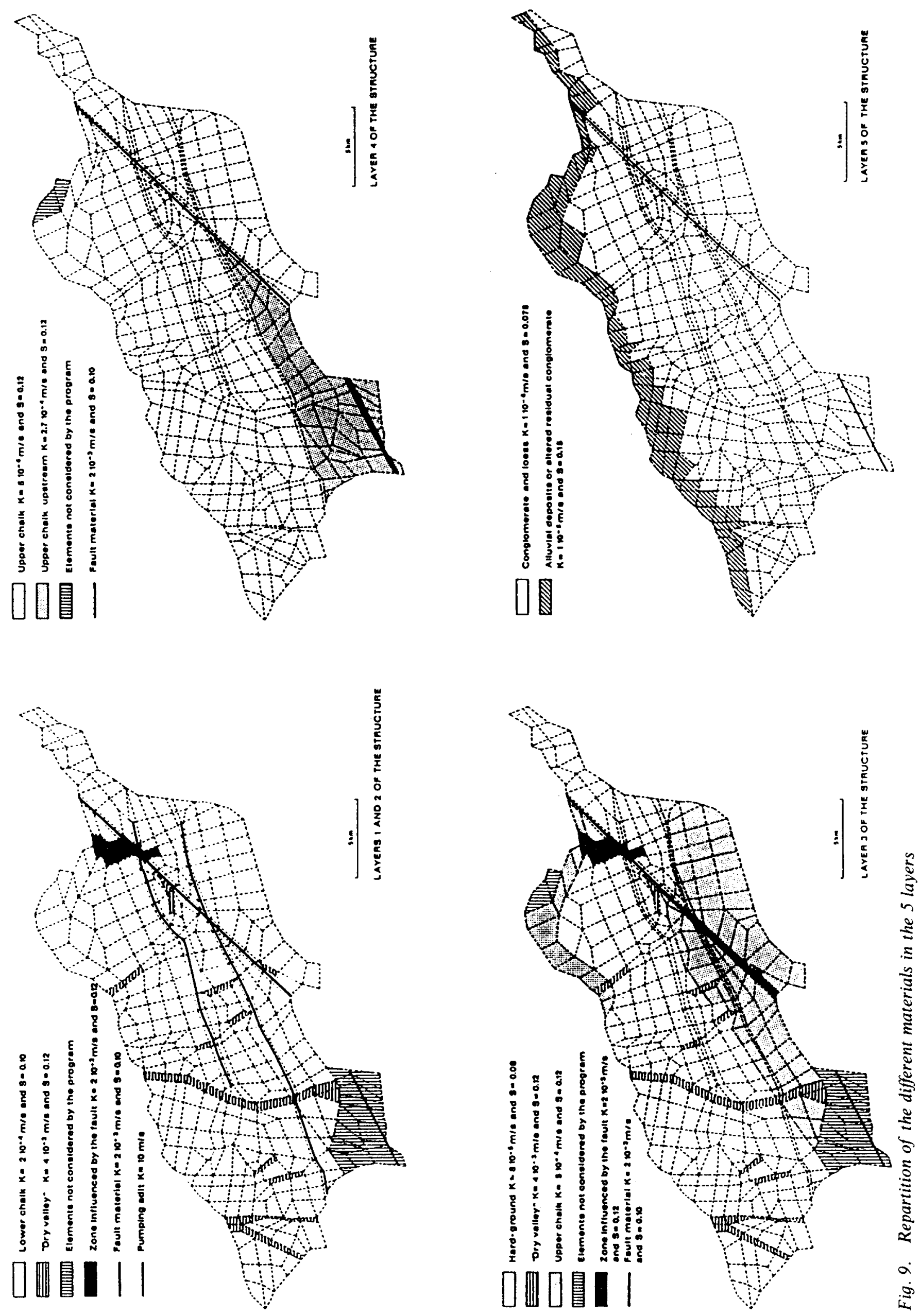

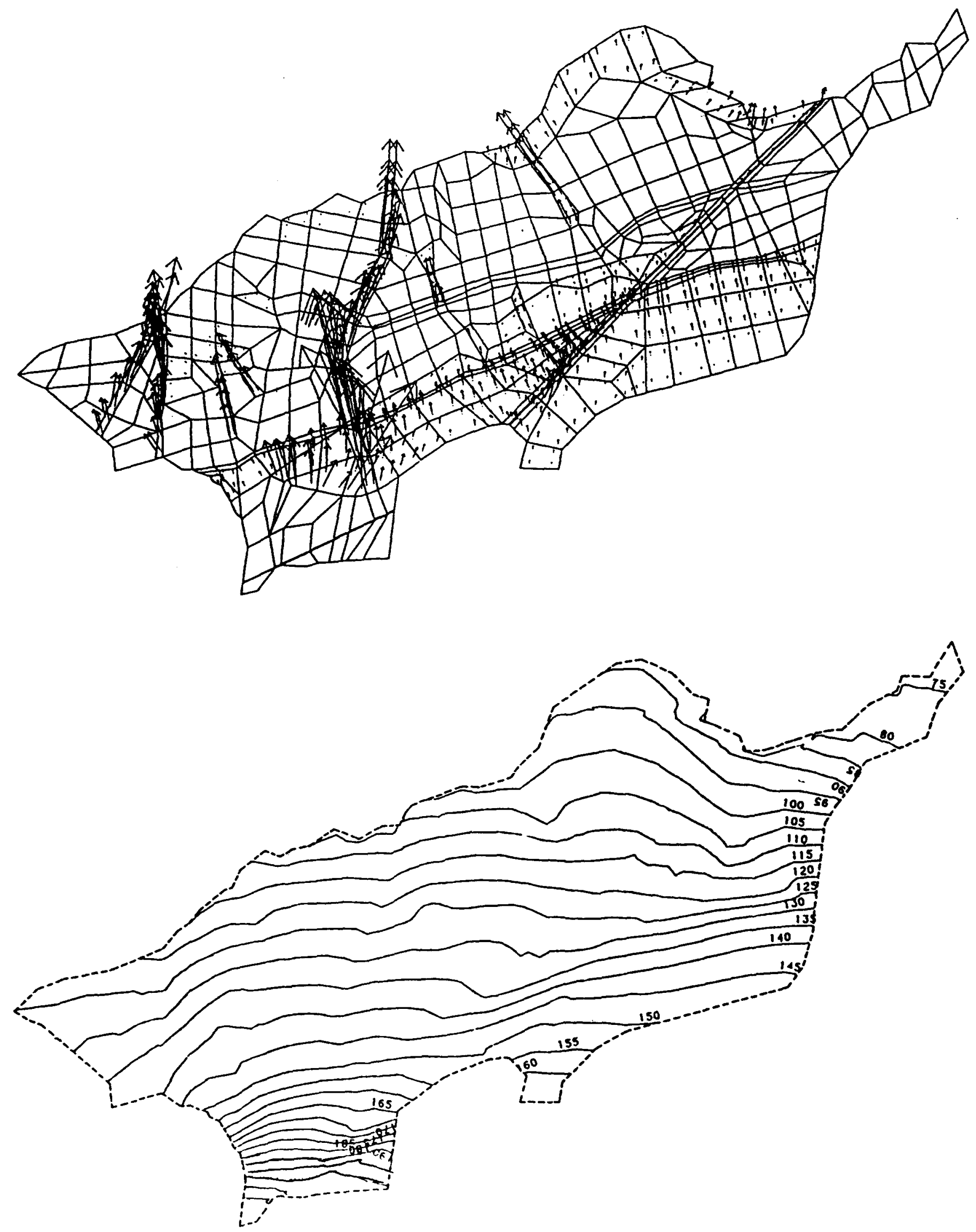

Fig. 10. Computed flow in the 3rd layer and computed piezometric map of 1966 
Large water table aquifer in transient conditions: $A$. Dassargues et al.

Material 8: upper chalk in the up-west zone:

$$
K=2.710^{-4} \mathrm{~m} / \mathrm{s} \text { and } S=0.12
$$

Material 9: new 'dry valley' in NE area, near the fault:

$$
K=2.10^{-3} \mathrm{~m} / \mathrm{s} \text { and } S=0.12
$$

The final repartition of these materials is shown on Fig. 9.

As an example of the results, Fig. 10 presents the computed flow map in the third layer and the piezometric map of the aquifer in 1966.

\section{CONCLUSIONS}

The complexity of the geological conditions in the whole modelled volume justifies fully the use of the finite element method. The modelling of the water table surface in transient conditions is realized with a fixed meshing network using a new storage law. This new method allows for spare computational time to study regional aquifers with a good accuracy.

The calibration procedure has been completed with care and the sensitivity of the model to variations of permeability or storage coefficient has been tested.

Nowadays, this model can be used for prediction and computations of future balances. The potential, gradients and flows can be computed for any year in function of the infiltration and pumping data. The model consumes at the present time about $30 \mathrm{CPU}$ hours on a Micro VAX II for the whole calibration simulation from 1951 to 1984 and with a time-step of one year.

\section{ACKNOWLEDGEMENT}

This work has been carried out under a contract with the Water Office of the Walloon Region of Belgium. The authors are grateful to Professors A. Monjoie and S. Cescotto (University of Liege) for the valuable help they have provided during the study.

\section{REFERENCES}

1 Brixko, A. L'alimentation en eau de l'agglomération liégeoise La technique de l'eau et de l'assainissement, 1980, (402-403), 8795

2 Calembert, L. Le Crétacé supérieur de la Hesbaye et du Brabant Ann. Soc. Géol. de Belgique, 1956, LXXX, 129-165

3 Dassargues, A., Monjoie, A., Charlier, R. and Radu, J. P Modelisation de la nappe aquifère de Hesbaye. Rapport MSMLGIH no. HESB/871, Université de Liège, unpublished. 1987

4 Monjoie, A. Observations nouvelles sur la nappe aquifère de la craie en Hesbaye, 1966

5 Charlier, R. Approche unifiée de quelques problèmes non linéaires de mécanique des milieux continus par la methode des éléments finis (grandes déformations des métaux. et des sols, contact unilateral de solides, conduction thermique et ecoulements en milieu poreux). Thèse de Doctorat. Collection des publications de la Faculté des Sciences Appliquées. No. 109. Université de Liège, Belgique, 1987

6 Taylor, R. L. and Brown, C. B. Darcy flow solution with a free surface, ASCE, Hydraulics Div., 1967, 93(HY2), 25-33

7 Desai, C. S. Finite element residual scheme for unconfined flow Int. J. Num. Meth. Eng., 1976, 10, 1415-1418

8 Desai, C. S. and $\mathrm{Li}, \mathrm{G}$. C. A residual flow procedure and application for free surface flow in porous media, Advances in Water Resources, 1983, 6, 27-35

9 Gioda, G. and Cividini, A. An analysis of unconfined steady state seepage, Eur. Conf. ECONMIG 86, Stuttgart, 1986

10 Bruch, E. Resolution par èlements frontières des écoulements permanents en milieu poreux à surface libre èventuellement indéterminée. Travail de fin d'études, Facultè des Sciences Appliquées, Université de Liège, 1985

11 Bruch, E. and Grilli, S. Computation of the transient seepage problem in anisotropic porous media by the boundary element method, 9th Int. Conf. on BEM, Stuttgart, Computational Mechanics Publications, 1987

12 Piette, Ch. Application des élèments finis à la determination de la surface piézometrique d'une nappe d'eau souterraine. Travail de fin d'études, Faculté des Sciences Appliquées, Université de Liège, 1976

13 Piette, Ch. and Cescotto, S. Application des éléments finis a la détermination de la surface piézométrique d'une nappe d'eau souterrain. Actes de la journée d'études sur la méthode des éléments finis appliquée à la géotechnique (ABEM), Bruxelles, 1983

14 Comini, G., de Guidice, S., Lewis, R. W. and Zienkiewicz, O. C. Finite element solution of non-linear heat conduction problems with special reference to phase change, Int. J. Num. Meth. in Eng.. 1974, 8, 613-624

15 Bathe, K. J. and Khoshgoftaar, M. R. Finite element free surface seepage analysis without mesh iteration, Int. J. Num. Anal. Meth. Geomech., 1979, 3, 13-22

16 Ghaboussi, J. and Wilson, E. L. Flow of compressible fluid in porous elastic media, Int. J. Num. Meth. Eng., 1973, 5, 419-442 